\title{
Implementation of a New Super Twisting Mode Algorithm Controlled by Dspace: Application to Series Multicell Converter
}

\author{
Mohamed Redha SKENDER, Abdelhalim TLEMCANI \\ Research Laboratory in Electrical Engineering and Automatic (LREA), \\ University of Medea, Ain D' heb, Medea, 26000, Algeria, \\ skender_mohamed@yahoo.fr, h_tlemcani@yahoo.fr
}

\begin{abstract}
In this paper, a control algorithm of higher order sliding mode was developed for a series multi cells converter to force floating voltages across capacitors to stay in their reference. The results of simulations were validated experimentally by a converter that has been realized for this task.
\end{abstract}

Keywords: nonlinear control, converter, sliding mode control, algorithm, chopper.

\section{Introduction}

The performances of electronic power converters have been evolving through the last decades, in an attempt to be more reliable and efficient. This has been carried out thanks to the developments of the semiconductor of power components and the new system of energy conversion. These high performances are directly linked to the converter's topology and its power electronic components.

Multicell converters are currently embedded in many electric devices. Their aim is to convert an electrical energy shape (voltage /current / frequency) to another one.

This new topology presents two additional advantages: the possibility of a modular construction and the possibility of using components having large diffusion.

On the other hand, the following model must be simple to allow real time control and precise enough to achieve the desired behaviour. Because it's based on continuous variables and discrete variables, multicell converter modelling is claimed to be difficult [19], [20]. According to previous studies, three types of models could be found. The average model consists in calculating average value of all variables during one sampling period. Nevertheless, this model cannot represent the capacitors terminal voltage natural balancing; the harmonic model based on the decomposition in Fourier series of control signals, which determine the harmonics phase and amplitude across the switches, also determining the harmonic current of the load to determine the evolution of capacitor voltages;
The instantaneous model considers all the switching over a period (discrete location). This model contains all information; it is generally used to validate controls or to use as observers [16], [19].

Various control methods have been proposed for the multicell converters, cite as nonlinear control based on input-output linearization [10], Robust Switching Control Systems with Input Delay [8], predictive control [5], [15], hybrid control [4], sliding mode control [1], [6], [17], Exponential Mapping Function [12].

In this work, we will apply and implement a new sliding mode controller to the load R-L connected to a multicell converter called super twisting mode. This control is very well adapted for this kind of converter, as we shall demonstrate in the subsequent sections.

Sliding mode control (SMC) [22] is a nonlinear control technique featuring remarkable properties of accuracy, robustness, and easy tuning and implementation.SMC systems are designed to lead the system states onto a particular surface in the state space, named sliding surface. Once the sliding surface has been reached, the sliding mode control keeps the states on the close neighborhood of the sliding surface. Hence The advantages of SMC are the dynamic behavior of the system can be adapted by the particular choice of the sliding function, and also the closed loop response becomes completely insensitive to uncertainties, disturbance and nonlinearity [23] [24].Sliding modes based controllers have witnessed major development these last years. Such an interest in sliding modes controllers can be explained by their intrinsic robustness 
property and the relative ease of application (see for example [2] [3] [7] [9] [11] [13] [18]).

In order to evaluate the feasibility and constraints of the sliding modes algorithm, the realization of an experimental model was proposed to validate the actual performance of the algorithm. The realized maquette is sized for educational or research applications. The bench includes a Dspace1103 card, a multicellular converter of three cells, a DC motor or a RL load. This bench allows:

- Define and associate the different hardware and software

- Develop control programs

- Applied sliding mode control techniques.

The main objective of this paper is to show that the multicellular converter is very well suited for a control set-up using sliding modes and which will be demonstrated by experiment.

\section{Problem Position}

In this section, we consider a nonlinear system whose dynamics is described by the differential system:

$$
\left\{\begin{array}{l}
\dot{x}=f(t, x, u) \\
s=s(t, x) \in \mathfrak{R} \\
u=u(t, x) \in \mathfrak{R}
\end{array}\right.
$$

Where:

$x=\left[x_{1}, \ldots, x_{n}\right]^{T} \in X: \quad$ represents the state vector, $X \subset \Re^{n}, \quad X \quad$ is a differentiable manifold or an open subset of $\mathfrak{R}^{n}$.

$u$ : represents the command.

$f:$ is assumed sufficiently differentiable function, but known so uncertain.

$t$ : is the time.

The system $\dot{x}=f(t, x, u)$ include those of the form: $\dot{x}=f(x)+g(x) u$.

The problem is always to force the trajectories of the system to evolve on the sliding surface

$$
s=\{x \in X: s(t, x)=0\}
$$

Being a real-valued function sufficiently differentiable such that its $(r-1)$ first derivatives with respect to time are functions of the state $x$ (which means they do not contain any discontinuity.) defines a submanifold of $(n-1)$ dimension called sliding surface or switching.

The function $s(t, x)$ is called a sliding function or switching function. It separates the state space in two separate parts $s(t, x)>0$ and $s(t, x)<0$.

\section{Sliding Mode Control}

The sliding mode control is a variable structure control can change in structure and switching between two values depending on a property specific switching logic $s(x)$.

The principle of sliding mode control is to constrain the system to reach a given surface called sliding surface and remain there until the balance. This control is done in two steps: the convergence towards the surface and then sliding along it (Figure 1.)

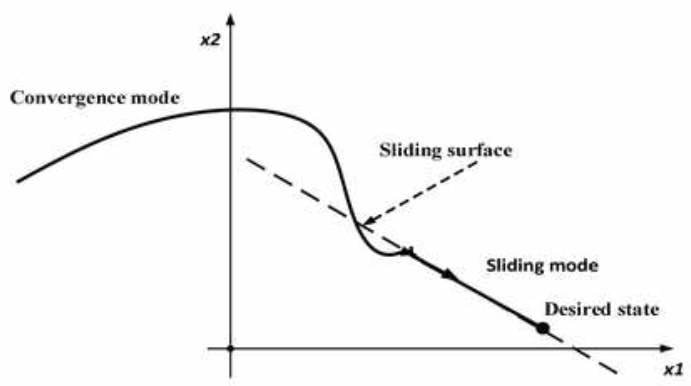

Figure 1. Different modes of convergence for the state trajectory

The synthesis of sliding mode control is done in three steps:

- Choice of the sliding surface

- Establish the convergence condition

- Determine the control law, which allows reaching the surface and remaining there.

\subsection{Choice of the sliding surface}

The choice of the sliding surface includes not only the necessary number of such surfaces but also form, depending on the application and the purpose. In general, for a system as defined by the following state equation:

$$
[X]=[A] \cdot[X]+[B] .[u]
$$

Where $[X] \in \mathfrak{R}^{n}$ is the state vector, $[u] \in \mathfrak{R}^{m}$ control vector, with $n>m$.

J. J. Slotine [21] provides a general form of equation (1) for determining the sliding surface, 
which ensures convergence of a variable value to its desired:

$$
s(x)=\left[\frac{d}{d t}+\lambda\right]^{r-1} e(x)
$$

with, $e(x)$ : the gap of the variable to adjust, $e(x)=X-X_{\text {ref }}$.

$\lambda$ : Positive constant that interprets the bandwidth of the desired control.

$r$ : relative degree, equal to the number of times to derive the output to bring up the control.

$s(x)=0$ : is a linear differential equation whose solution is the only: $e(x)=0$, this implies that the state of the system is equal to the desired state.

\subsection{Convergence and existence conditions}

The choice of the sliding function is done, the second step is to design a control law that would lead the state vector to converge to the surface and remain $s(x)=0$. For this, it is necessary that the control law is designed such that $s$ is attractive.

To determine the attractiveness condition, consider the Lyapunov function, Lyapunov Function is a positive scalar function $V(x)>0$ for the state variables of the system. The control law is to decrease this $\dot{V}(x) \prec 0$ function. The idea is to choose a $s(x)=0$ scalar function to ensure the attraction of the control variable to its reference value and design a $u$ control such that the square of the surface is Lyapunov function. We define the Lyapunov function as follows:

$$
V(x)=\frac{1}{2} s^{T}(x) s(x)
$$

For the $V(x)$ function can decrease, just ensure that its derivative is negative. This is checked only if the condition (2) was verified.

Equation (3) explains that the square of the distance between a point in the phase plane and the sliding surface expressed by $s^{T}(x) s(x)$ is decreasing all the time, forcing the trajectory of the system to towards the surface from both sides thereof. This condition requires an ideal sliding regime or the switching frequency is infinite.

For convergence in finite time, condition (4) which guarantee that asymptotic convergence to the sliding surface is replaced by a more restrictive condition called $\boldsymbol{\eta}$-attractiveness and given by: [20]

$$
\dot{s} . s \leq-\eta|s|, \eta>0
$$

\subsection{Super twisting algorithm}

This algorithm has been developed for the servo systems relative degree equal to 1 with respect to the sliding surface. Emelyanov proposed this control law [7].

It was studied by Levant in [14]. The Supertwisting does not use information about $\dot{s}$ this can be seen as an advantage. It is composed of two parts, a $u_{2}$ discontinuous part and a $u_{1}$ continuous part:

$u=u_{1}+u_{2}$

$u_{1}=\left\{\begin{array}{cc}-u & \text { si }|u|>1 \\ -W \operatorname{sign}(s) & \text { si }|u| \leq 1\end{array}\right.$

$u_{2}=\left\{\begin{array}{cc}-\lambda_{1}\left|s_{0}\right|^{p} \operatorname{sign}(s) & \text { si }|s|>s_{0} \\ \lambda_{1}\left|s_{0}\right|^{p} \operatorname{sign}(s) & \text { si }|s| \leq s\end{array}\right.$

This controller can be simplified if the control system is linearly dependent on the control and the law control is given by:

$\left\{\begin{array}{l}u=\lambda|s|^{\frac{1}{2}} \operatorname{sign}(s)+v \\ \dot{v}=-W \operatorname{sign}(s)\end{array}\right.$

The interest of this algorithm is that it very robust; it does not need information about the derivative of $s$. Because of this characteristic can reduce the number of sensors in the system, and the calculation time.

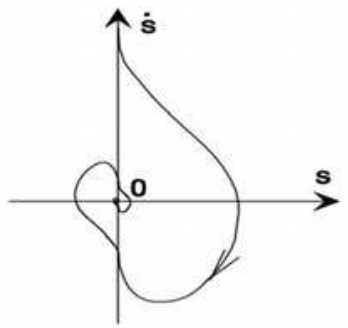

Figure 2. Convergence of Super Twisting algorithm in the $(\dot{s} . s)$

The trajectory of the algorithm in the $(\dot{s} . s)$ phase plane is given in Figure 2, and shows that the consecutive intersections thereof with the axes of the plane ( $\dot{s} . s)$ evolve while approaching the origin is reached in finite time.

By a particular choice of the model and of the sliding surface, the sliding mode control 
algorithm (Super Twisting) [7] [9] can be formulated as an observation algorithm for estimating the derivative of a signal measured.

\section{Application of Super Twisting Control to Series Multicells Converter}

\subsection{Series multicells converter structure}

The general diagram of multi cells chopper is shown in Figure 3. [19]. It consists of $p$ pair semiconductor, separated by $(p-1)$ floating capacitors. The two switches in each pair must always be in the opposite condition, in order to avoid a short circuit of voltage sources. This is obtained by control of two IGBT with almost opposite signals integrating downtime with each switching. For this reason, each pair is a cell switching. The principle of this topology is to split the voltage of the DC bus voltage of $p$ elementary sources.

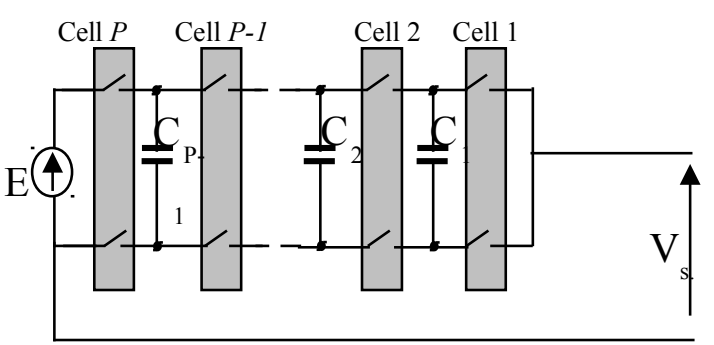

Figure 3. A series multi cells converter

The multicells converter as it was defined and modeled is a nonlinear multi-input variable structure system. Define a sliding mode control of such a system is equivalent to setting $p$ sliding surfaces (each switching cell is a $s_{i}(x)=0$ surface of $(n-1)$ dimension) associated with that switching law properly allow the stability and the existence of a sliding regime on the intersection of all surfaces. The trajectory evolution of the system with respect to the position of the surface determines the state of the switches.

$$
\dot{x}=f(x)+\sum_{i=1}^{p} g_{i}(x) u_{i}=f(x)+G(x) U
$$

By a change of variable, we can define the dynamics of the converter according to the error:

$$
\begin{aligned}
& \Delta \dot{x}=f(x)+G(x) U e q+G(x) \Delta U \\
& \text { or: } \Delta U=U-U_{e q} .
\end{aligned}
$$

With $U_{e q}$ : the equivalent command to keep the system in steady state.
The choice of the Lyapunov function $V$ is based on the simplicity the control law of implementation. Other choices of the Lyapunov function can be considered and ensure better performance by imposing a dynamic or minimizing a quadratic criterion [17]. The following Lyapunov function:

$$
V(\Delta x)=\frac{1}{2} \Delta x^{T} \cdot Q \cdot \Delta x
$$

In addition, its time derivative of $V$ is:

$$
\dot{V}(\Delta x)=\frac{1}{2} \Delta x^{T} \cdot Q \cdot \Delta \dot{x}
$$

Where: $Q=\operatorname{diag}\left(C_{1} C_{2} \ldots C_{P_{-1}} L\right)$

$$
\begin{aligned}
& \Delta x^{T}=x-X e q= \\
& =\left[v_{c 1}-\frac{\mathrm{E}}{p} v_{c 2}-\frac{2 \mathrm{E}}{p} \ldots v_{c p-1}-\frac{(p-1) \mathrm{E}}{p} i-I_{\text {ref }}\right]^{T} \\
& X r e f=\left[\begin{array}{llll}
\frac{\mathrm{E}}{p} & \frac{2 \mathrm{E}}{p} & \ldots & \frac{(n-1) \mathrm{E}}{p} \mathrm{I}_{\mathrm{ref}}
\end{array}\right]
\end{aligned}
$$

After demonstration [17], we then choose $p$ switching functions:

$$
s_{i}(x)=-\Delta x^{T} \cdot Q \cdot g_{i}(x)
$$

As a result, the state of the switches is a function of $p$ switching functions. The state of each switch is defined by:

$$
u_{i}=\left\{\begin{array}{lll}
1 & \text { si } & s_{i}(x)>0 \\
0 & \text { si } & s_{i}(x)<0
\end{array}\right.
$$

\subsection{Calculation of switching functions}

We can now define the control laws that ensure stability of the $X_{\text {ref }}$ equilibrium point using the results of the previous section for a three cells converter.

The switching functions $s_{1}, s_{2}$ and $s_{3}$ obtained is following:

$$
\left\{\begin{aligned}
s_{1}(x) & =-\Delta x^{T} \cdot Q \cdot g_{1}(x)= \\
& =I_{\text {ref }} v_{c 1}-\frac{E}{3} I_{\mathrm{ch}} \\
s_{2}(x) & =-\Delta x^{T} \cdot Q \cdot g_{2}(x)= \\
& =I_{\text {ref }}\left(v_{c 2}-v_{c 1}\right)-\frac{E}{3} I_{\mathrm{ch}} \\
s_{3}(x) & =-\Delta x^{T} \cdot Q \cdot g_{3}(x)= \\
& =I_{\mathrm{ref}}\left(E-v_{c 2}\right)-\frac{E}{3} I_{\mathrm{ch}}
\end{aligned}\right.
$$


After some transformations [17], these functions are homogeneous form a current rewritten as follows:

$$
\left\{\begin{array}{l}
s_{1}(x)=\frac{3 \mathrm{I}_{\mathrm{ref}}}{E} v_{s c 1}-I_{\mathrm{ch}} \\
s_{2}(x)=\frac{3 \mathrm{I}_{\mathrm{ref}}}{E}\left(v_{c 2}-v_{c 1}\right)-I_{\mathrm{ch}} \\
s_{3}(x)=\frac{3 \mathrm{I}_{\mathrm{ref}}}{E}\left(E-v_{c 2}\right)-I_{\mathrm{ch}}
\end{array}\right.
$$

\subsection{Super twisting control of a three cells chopper}

The control scheme is shown in Figure 4.

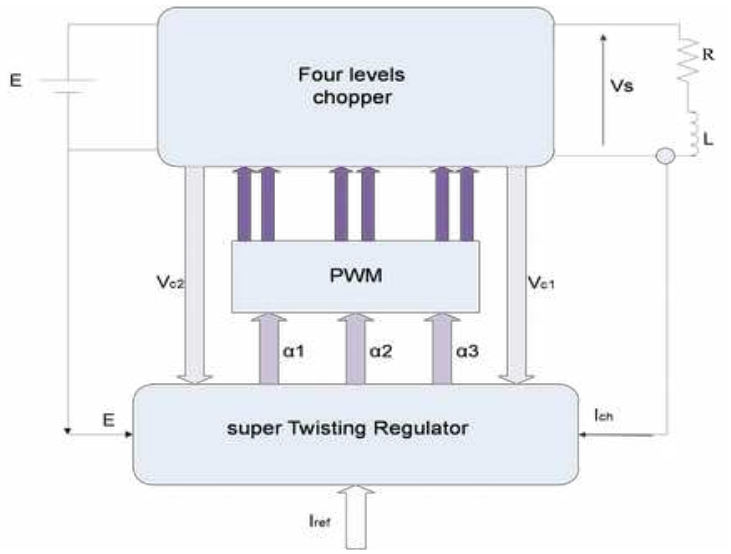

Figure 4. Structure of Super Twisting control

The proposed control strategy is based on the Super Twisting algorithm. In this context, we consider the sliding surfaces in (17):

The relative degree for that subsystem $(r=n=1)$. When $(r=1)$, the law control is the Super Twisting law:

The duty ratios are calculated by the following law control in (9):

$$
\left\{\begin{array}{l}
\alpha_{i}=\lambda_{i}|s|^{\frac{1}{2}} \operatorname{sign}\left(s_{i}\right)+v \\
\dot{v}=-W_{i} \operatorname{sign}(s) \\
\text { avec }: i=1,2,3
\end{array}\right.
$$

\subsection{Simulation results:}

We will validate the dynamic performance of the law control using a simulation in Simulink for a converter (chopper) with the following characteristics:

$$
\left\{\begin{array}{l}
C_{1}=C_{2}=40 \mu F \\
L=0.5 \mathrm{mH} \\
R=10 \Omega
\end{array}\right.
$$

The following command sequence is used:
- The voltage source is $1500 \mathrm{~V}$, the reference current is $80 \mathrm{~A}$.

- At $\mathrm{t}=0.25 \mathrm{~s}$, the source voltage is set to $\mathrm{E}$ $=1800 \mathrm{~V}$.

We use a regulator with the following parameters:

$\left\{\begin{array}{l}\lambda_{1}=\lambda_{2}=\lambda_{3}=20 \\ W_{1}=W_{2}=W_{3}=10\end{array}\right.$

Our objective is to regulate the voltages $v_{c 1}$ and $v_{c 2}$ of capacitors their references $E / 3$ and $2 E / 3$ the load current must reach its reference value $I_{\text {ref }}=80 \mathrm{~A}$.

A value $I_{\text {ref }}$ reference current is independent of the load. We obtained the following results:
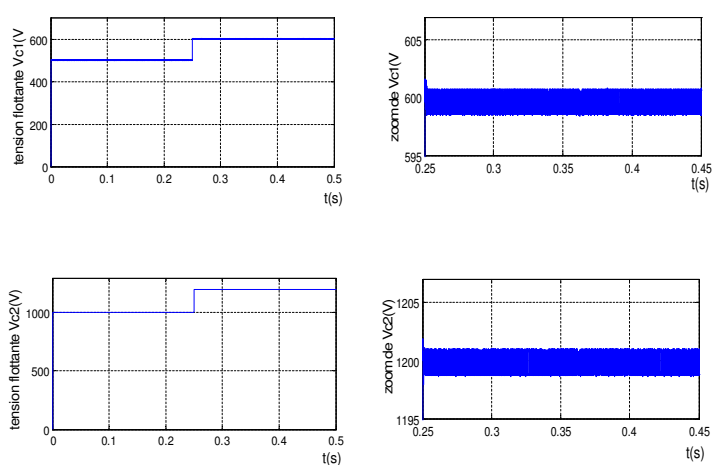

Figure 5. Evolution of the $v_{c 1}$ and $v_{c 2}$ floating voltage

The Figure 5. shows the evolution of floating voltages, tensions quickly to assess steady state, before and after the change of the reference voltage at time $(\mathrm{t}=0.25 \mathrm{~s})$ we find that the two voltages $v_{c 1}$ and $v_{c 2}$ respectively to stabilize at $E / 3$ and $2 E / 3$, and the phenomenon of chatter is gone.
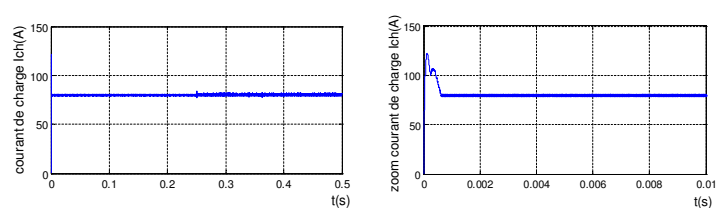

Figure 6. Evolution of the $\mathrm{I}_{\mathrm{ch}}$ load current.

The Figure 6. represents the evolution of the $I_{c h}$ load current, it is clear that current enslaves a reference value, that is to say, the static error is equal to $0.3 \mathrm{~A}$. and after the zoom, the current has exceeded Due to speed of response that characterizes the law of the synthesized sliding mode control. 
We note that the two voltages $v_{c 1}$ and $v_{c 2}$ and charging current $I_{c h}$ follow their references.
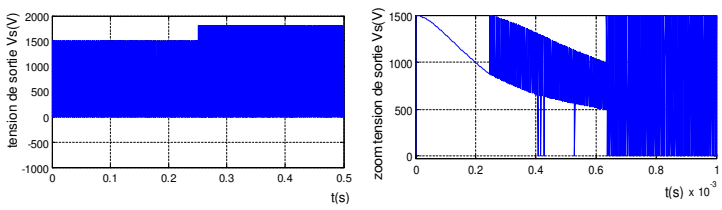

Figure 7. Evolution of the VS output voltage

The evolution of the output voltage is represented in Figure 7, and in zoom Figure it is clear that the four levels $E, E / 3,2 E / 3$ and 0 are present regardless of the changes to the sequence reference voltage.
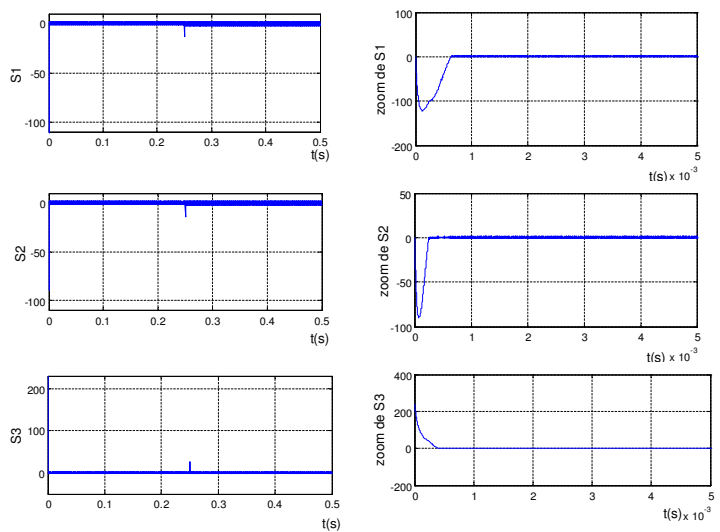

Figure 8. Evolution of the sliding surfaces.

Figure 8. shows the evolution of three switching surfaces, they present the switching of around 0 . When a variation of the reference voltage reaches the surfaces move away from the value 0 but return very quickly to cancel super command.

\section{Description of the Experimental Bench}

In order to validate experimentally the control techniques presented in the context of this work, we have built a complete test bench at our laboratory (LREA). The photo of this experimental bench is given in Figure 9. consists of a multicellular arm for three cells. The switches consist of the IGBT transistors connected in antiparallel with the diodes. IGBTs are associated with control modules manage downtime and protection against short circuits.

IGBT control signals are derived from a DS1103 Dspace card, based on a processor dedicated to signal processing the TMS320F240 from Texas Instruments.

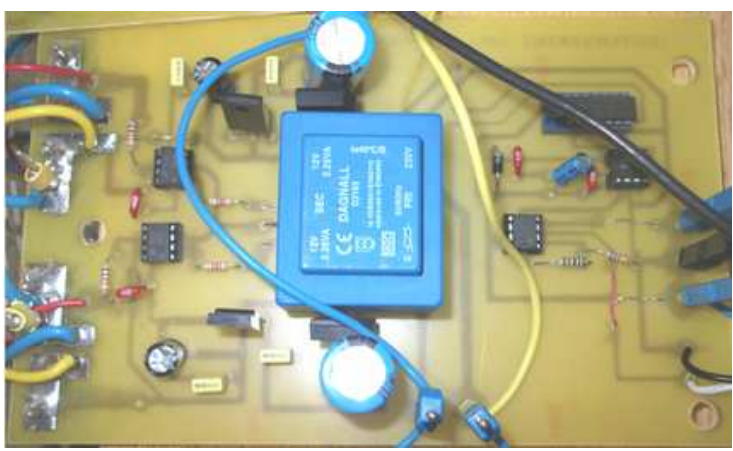

Control card and drivers

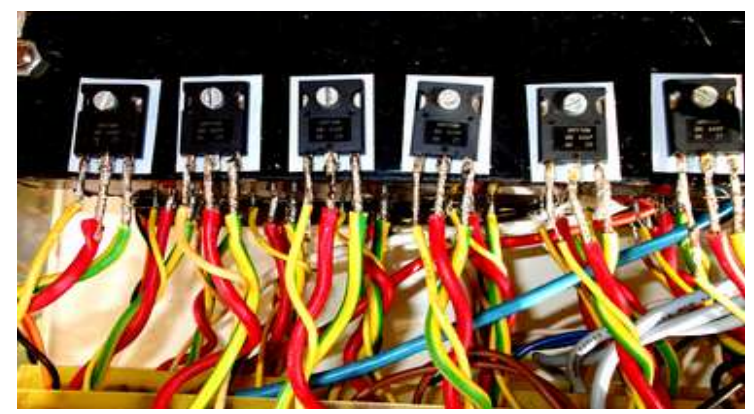

IGBT switches

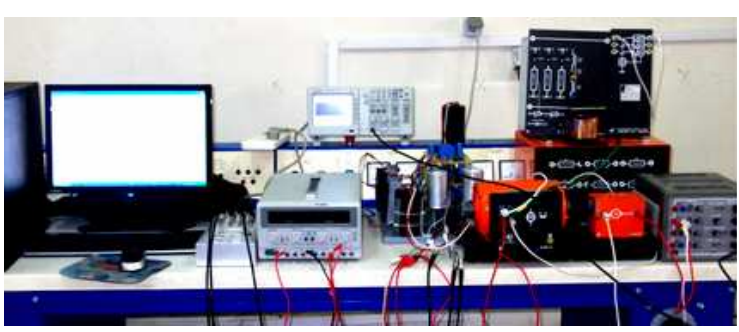

Complet bench

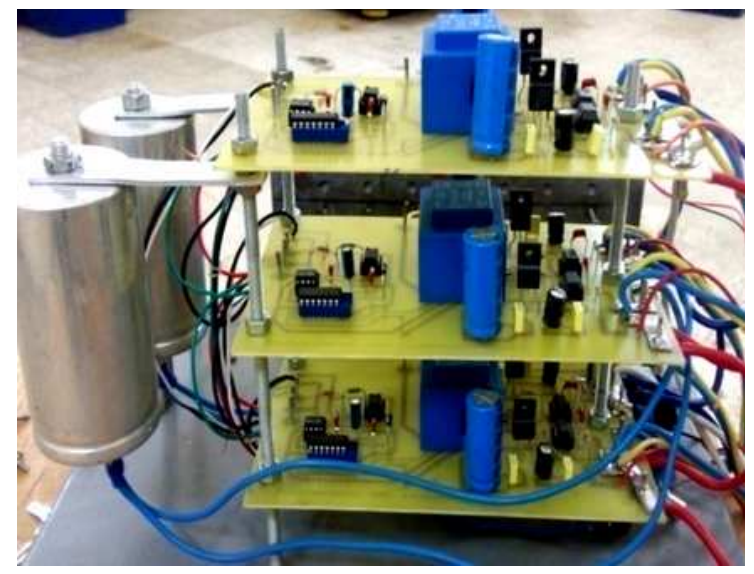

Control card and capacitors

Figure 9. Photos of the experimental bench of series multi cell arms.

The Figure 9. shows the photos of bench realized:

- The power part consists of a multicellular converter for three cells (control card and 
drivers, IGBT switches, capacitors, the RL load or DC motor,

- The measurement part of voltage and current,

- The control part represented by the DS1103 control card controlled by computer.

\subsection{Experimental results}

In this section, we present experimental results obtained on a series multi cells chopper with three-cell (four levels) of RL load, whose characteristics are:

The supply voltage $\mathrm{E}=60 \mathrm{~V}$

The values of the capacitors $\mathrm{C}_{1}=\mathrm{C}_{2}=50 \mu \mathrm{F}$

The switching frequency $\mathrm{f}_{\text {dec }}=10 \mathrm{KHz}$

The load resistance $\mathrm{R}=470 \Omega$

The load inductance $\mathrm{L}=2,5 \mathrm{mH}$

The modulation frequency $\mathrm{f}_{\bmod }=100 \mathrm{~Hz}$

Note: in the majority of results the (sonde $\times 10$ of oscilloscope)

Figures 10, 11 and 12 show the output voltage across the RL load, switches between different levels.

Level 1 and 2: level 0 to $E / 3$, we have the following results

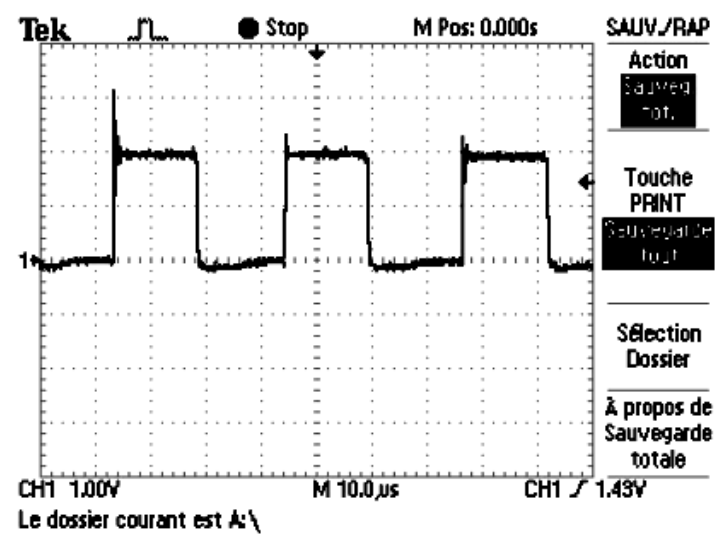

Figure 10. Voltage across the RL load

The evolution of the output voltage is represented in zoom Figure 10. it is clear that the levels 0 and $E / 3$ respectively 0 and $60 / 3=20 \mathrm{~V}$ present regardless of the changes to the sequence reference voltage.

Level 2 and 3: level $E / 3$ to $2 E / 3$, we have the following results

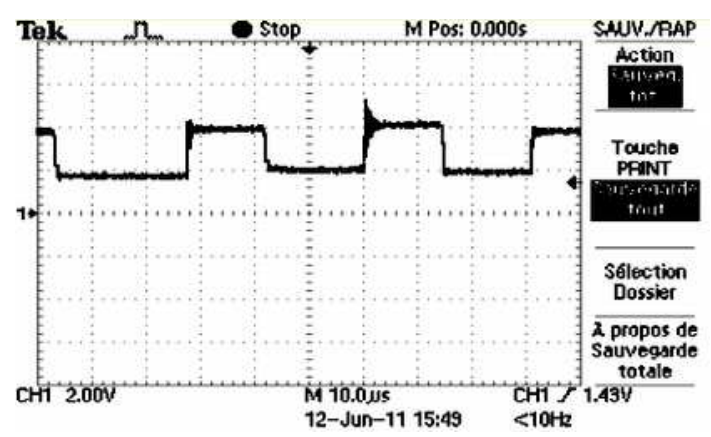

Figure 11. Voltage across the RL load

The evolution of the output voltage is represented in zoom Figure 11. it is clear that the levels $E / 3$ and, $2 \mathrm{E} / 3$ respectively $60 / 3=20 \mathrm{~V}$ and $2 \times 60 / 3=40 \mathrm{~V}$ present regardless of the changes to the sequence reference voltage.

Level 3 and 4: levels 2E/3 and E, we have the following results

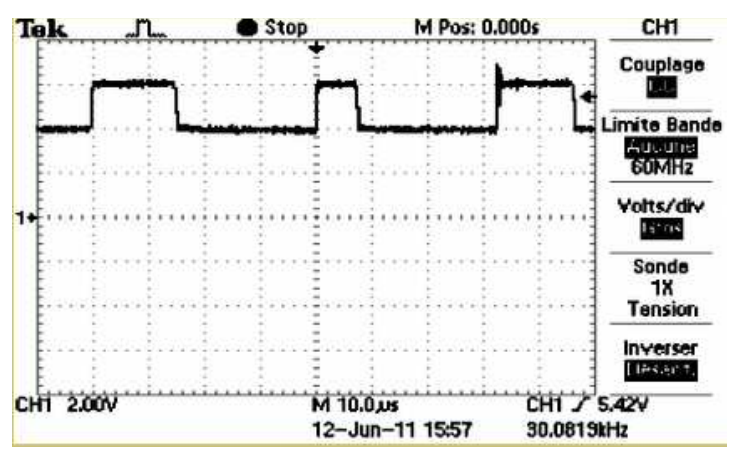

Figure 12. Voltage across the RL load

The evolution of the output voltage is represented in zoom Figure 12. it is clear that the levels 2E/3 and, $E$ respectively $2 \times 60 / 3=40 \mathrm{~V}$ and $E=60 \mathrm{~V}$ present regardless of the changes to the sequence reference voltage.

The results revealed that the output voltage switches between level 1 and level 2, between level 2 and level 3, between level 3 and level 4 respectively. During the first interval the output voltage switches between 0 and $\mathrm{E} / 3$ values, and in the second the output voltage switches between $E / 3$ and $2 E / 3$ and the third interval the output voltage switches between $2 \mathrm{E} / 3$ and, values with the $\mathrm{E}$ input voltage equal to $60 \mathrm{~V}$.

These results confirm the simulation study in Section 4, Figure 7. In all three cases note a satisfactory behaviour of the dynamics of the voltages across the capacitors can be seen and the ripple of the output voltage is divided by three. 
In all three cases, the evolution of the voltage across the capacitors, are steady in their level of voltages reference such that $E / 3$ and $2 \mathrm{E} / 3$.

We obtained the following results as shown in Figure 13:

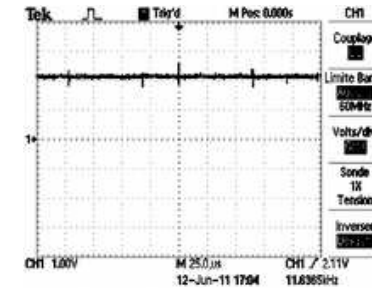

(a) voltage $v_{c 1}$ across capacitor $\mathrm{C} 1$

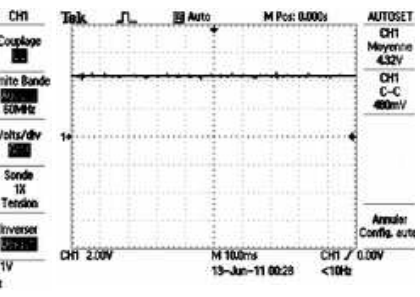

(b) voltage $v_{c 2}$ across capacitor $\mathrm{C} 2$
Figure 13. Evolution of the $v_{c 1}$ and $v_{c 2}$ voltages across the capacitors.

Robustness test: Is to test the robustness of system, the variation of the $\mathrm{E}$ input voltage of $60 \mathrm{~V}$ to $30 \mathrm{~V}$ voltage and show the variation of the voltages $v_{c 1}$ and $v_{c 2}$ across the capacitors.

The experimental results are given in Figure 14 as follows:

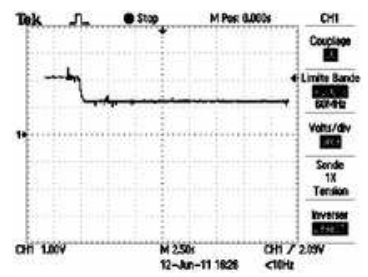

(a) voltage $v_{c 1}$ across capacitor $\mathrm{C} 1$

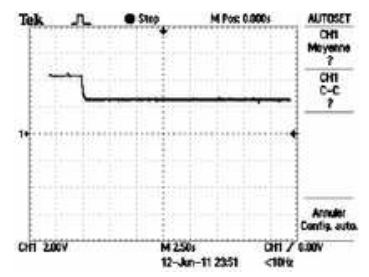

(b) voltage $v_{c 2}$ across capacitor $\mathrm{C} 2$
Figure 14. The variation of the voltage across the $v_{c 1}$ and $v_{c 2}$ capacitor.

Despite the variation of the input voltage, the voltages across the capacitors follows their reference voltages such as $v_{c 1}$ varies from $20 \mathrm{~V}$ to $10 \mathrm{~V}$ and $v_{c 2}$ from $40 \mathrm{~V}$ to $20 \mathrm{~V}$ as shown in Figure 14.

\subsection{Application to an active load (DC motor):}

Figure 15 presents experimental results for a series multicell chopper with 3 cells, supplied an active load (DC motor).

It is noted that the motor speed varies with different variations of the voltage, therefore based on the average value of the output voltage.

Note: Results are made with a ratio voltage sensor $400 / 2.5$ and a tachometer has coefficient of 0.02 .

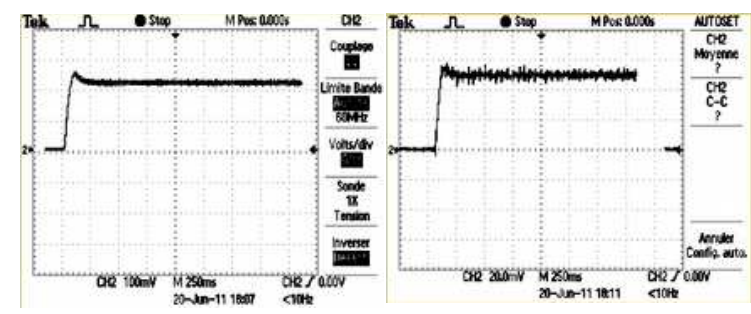

(a) the motor speed in level 4

(b) the motor speed in level 2

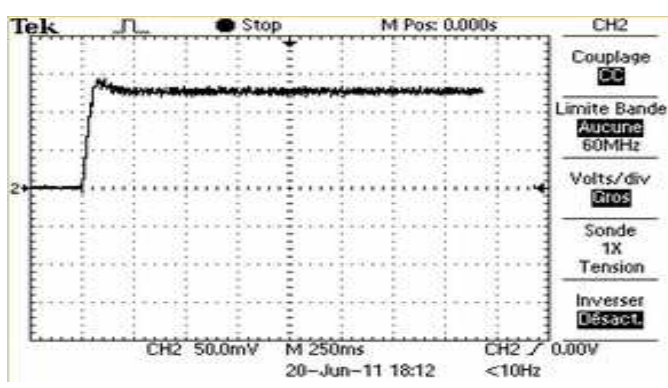

(c) the motor speed in level 3

Figure 15. Detected speed to a DC motor.

Despite the variation of the output voltage, the voltages across the capacitors follows their reference voltages such as $v_{c 1}$ varies from $40 \mathrm{~V}$ and $v_{c 2}$ from $20 \mathrm{~V}$ as shown in Figure 16.

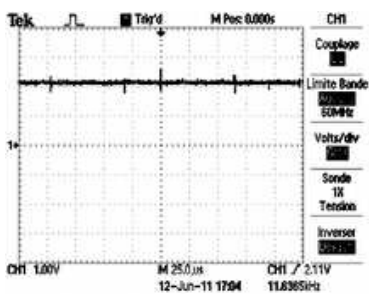

(a) voltage $v_{c 1}$ across capacitor $\mathrm{C} 1$

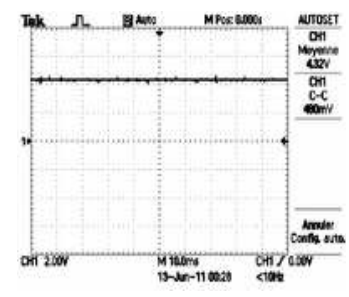

(b) voltage $v_{c 2}$ across capacitor $\mathrm{C} 2$.
Figure 16. Evolution of the $v_{c 1}$ and $v_{c 2}$ voltages across the capacitors.

\section{Conclusion}

To validate the simulation results, we realize an arm of series multicell Converter for three cells. And after different tests done on the converter (chopper operation), we find that the experimental results approximate to that of the simulation indicating that the algorithm of sliding mode control applied is very robust matter for a passive load (RL) or active (DC motor).

In summary, the evolution of the voltages across the capacities for different tests remains at levels of references. 


\section{REFERENCES}

1. AMET, L., M. GHANES, J.P . BARBOT, Direct Control Based on Sliding Mode Techniques for Multicell Serial Chopper, in American Control Conference (ACC), vol. 29 (1), 2011, pp. 751-756.

2. BENMANSOUR, K., A. BENALIA, M. DJEMAI, J. DELEON, Hybrid Control of Multicellular Converter, Nonlinear Analysis: Hybrid Systems, vol. 1 (1), 2007, pp. 16-29.

3. BENSAID, R., M. FADEL, T. MEYNARD, Observer Design for $A$ Three Cells Chopper Using DiscreteTime Model, Electromotion, vol. 2 (0), 1999, pp. 689-694.

4. BIAJA, M., D. PATINO, H. CORMERAIS, P. RIEDINGER, J. BUISSON, Hybrid Control of a Three-Level Three-Cell DCDC Converter, in American Control Conference (ACC), 2007, pp. 5458-5463.

5. DEFAY, F., A. LIOR, M. FADEL, A Predictive Control with Flying Capacitor Balancing of a Multicell Active Power Filter, IEEE Trans. on Ind. Electronics, vol. 55 (9), 2008, pp. 3212-3220.

6. DJEMAI, M., K. BUSAWON, K. BENMANSOUR, A. MAROUF, HighOrder Sliding Mode Control of a DC Motor Drive Via a Switched Controlled Multi-Cellular Converter, International Journal of Systems Science, vol. 42 (11), pp. 1869-1882, 2011.

7. EMELYANOV, S. V., S. K. KOROVIN, L. $\mathrm{V}$. LEVANTOVSKII, Higher Order Sliding Mode in the Binary Control System, Soviet Physics vol. 31 (4), 1986, pp. 291-293.

8. FILIPOVIC, V., Robust Switching Control Systems with Input Delay, Studies in Informatics and Control, ISSN 1220-1766, vol. 20 (4), 2011, pp. 411-420.

9. FLOQUET, T., J. P. BARBOT, W. PERRUQUETTI, Second Order Sliding Mode Control of Induction Motor, IEEE Conf. on Decision and Cont., Australia, vol. 2 (0), 2000, pp. 1691-1696.

10. GATEAU, G., M. FADEL, P. MAUSSION, R. BENSAID, T. MEYNARD, Multicell Converters: Active Control and
Observation of Flying-Capacitor Voltages, IEEE Trans. on Industrial Electronics, vol. 49(5), 2002, pp. 998-1008.

11. GULDNER, J., V. I. UTKIN, J. SHI, Sliding Mode Control in Electromechanical Systems, Taylor \& Francis, 1999.

12. HiLdEBRANDO, C., P. PAGLIONE, C. RIBEIRO, Exponential Mapping Function for Nonlinear Control, Studies in Informatics and Control, ISSN 12201766, vol. 24 (4), 2015, pp. 449-460.

13. LEVANT, A., Robust Exact Differentiation Via Sliding Mode Technique, Automatica, vol. 34 (3), 1998, pp. 379-384.

14. LEVANT, A., Universal SISO SlidingMode Controllers with Finite-time Convergence, IEEE Trans. on Automatic Control, vol. 46 (9), 2001, pp. 1447-1451.

15. LEZANA, P., R. AGUILERA, D. QUEVEDO, Model Predictive Control of an Asymmetric Flying Capacitor Converter, IEEE Trans. on Ind. El., vol. 56(6), 2009, pp. 1839-1846.

16. LIENHARDT, A. M., G. GATEAU, T. MEYNARD, Digital Sliding-Mode Observer Implementation Using FPGA, IEEE Trans. Industrial Electronics, vol. 54 (4), 2007, pp. 1865-1875.

17. MERADI, S., K. BENMANSOUR, K. HERIZI, M. TADJINE, M. BOUCHERIT, Sliding Mode and Fault Tolerant Control for Multicell Converter Four Quadrants, Electric Power Systems Research, vol. 95(0), 2013, pp. 128-139.

18. MEYNARD, T., H. FOCH, French Patent No. 91,09582 du 25 juillet 1991, depot international PCT (Europe, Japan, USA, Canada), No. 92,00652 du 8 juillet 1992.

19. MEYNARD, T., H. FOCH, P. THOMAS, J. COURAULT, R. JAKOB, M. NAHRSTAEDT, Multicell Converters: Basic Concepts and Industry Applications, IEEE Trans. Industrial Electronics, vol. 49 (5), 2002, pp. 955-964.

20. PATINO, D., P. RIEDINGER, C. LUNG, Predictive Control Approach for Multicellular Converters, in Procs. 2008 IEEE IECON, Nov. 2008, pp. 3309-3314. 
21. SLOTINE, J.-J. E., W. LI, Applied Nonlinear Control, London: Prentice-Hall, Inc. 1991.

22. STANISA, L. P., S. A. DRAGAN, D. N. VLASTIMIR, B. M. DARKO, T. M. MARKO, S. N. SASA, A New Approach to The Sliding Mode Control Design: Anti-Lock Braking System as A Case Study, Journal of Electrical Engineering, vol. 65 (1), 2014, pp. 37-43.

23. WANG, H. P, C. VASSEUR, V. CONCAR, A. CHAMROO, N. CHRISTOV, Design and
Implementation of Robust Hybrid Control of Vision Based Under Actuated Mechanical Non-Minimum Phase Systems, Studies in Informatics and Control, vol. 19 (1), 2010, pp. 35-44.

24. WANG, H., V. KONCAR, N. CHISTOV, C., VASSEUR, O. CHAMRO, Sampled Tracking for Delayed Systems Using Two-Time-Scale Sampled-data Controllers, Studies in Informatics and Control, vol. 19 (4), 2010, pp. 339-346. 